\title{
A comprehensive review on RAGE-facilitated pathological pathways connecting Alzheimer's disease, diabetes mellitus, and cardiovascular diseases
}

\author{
Agnila Chakraborty ${ }^{\dagger}$, Saad Ahmed Sami ${ }^{*}$ (i) and Kay Kay Shain Marma ${ }^{\dagger}$
}

\begin{abstract}
Background: Alzheimer's disease (AD), cardiovascular disease (CVD), and diabetes are some of the most common causes of morbidity and mortality among the aging populations and cause a heavy burden on the worldwide healthcare system. In this review, we briefly highlighted cellular inflammation-based pathways of diabetes mellitus and CVD through receptor for advanced glycation end products AGEs or RAGE leading to Alzheimer's disease and interrelation between these vascular and metabolic disorders. The articles were retrieved from Google Scholar, Science Direct, and PubMed databases using the following terms: Alzheimer's; AGEs; RAGE; RAGE in Alzheimer's; AGEs in Alzheimer's; RAGE in diabetes; RAGE related pathways of CVD; RAGE in hypertension; RAGE and RAS system; RAGE and oxidative stress.

Main body of the abstract: $A D$ is a neurodegenerative disease characterized by cognitive dysfunction and neuronal cell death. Vascular complications like hypertension, coronary artery disease, and atherosclerosis as well as metabolic syndromes like obesity and diabetes are related to the pathophysiology of AD. RAGE plays significant role in the onset and progression of AD. Amyloid plaques and neurofibrillary tangles (NFT) are two main markers of AD that regulates via RAGE and other RAGE/ligands interactions which also induces oxidative stress and a cascade of other cellular inflammation pathways leading to AD. Though AD and diabetes are two different disorders but may be inter-linked by AGEs and RAGE. In long-term hyperglycemia, upregulated AGEs interacts with RAGE and produces reactive oxygen species which induces further inflammation and vascular complications. Aging, hypercholesterolemia, atherosclerosis, hypertension, obesity, and inflammation are some of the main risk factors for both diabetes and dementia. Chronic hypertension and coronary artery disease disrupt the functions of the blood-brain barrier and are responsible for the accumulation of senile plaques and NFTs.
\end{abstract}

Short conclusion: RAGE plays a role in the etiology of $A \beta$ and tau hyperphosphorylation, both of which contribute to cognitive impairment. So far, targeting RAGE may provide a potential sight to develop therapies against some metabolic disorders.

Keywords: Alzheimer's disease, RAGE, AGEs, Oxidative stress, Inflammation, Diabetes, Cardiovascular disease

*Correspondence: s.a.sami18pharm@gmail.com

${ }^{\dagger}$ Agnila Chakraborty, Saad Ahmed Sami and Kay Kay Shain Marma contributed equally to this work.

Department of Pharmacy, Faculty of Biological Sciences, University of Chittagong, 4331 Chittagong, Bangladesh

\section{Background}

Alzheimer's disease (AD) is one of the most common causes of dementia for humans of old age. Extensive studies have suggested that the pathological changes that take place in the $\mathrm{AD}$ brain include the formation 
of senile plaques (SP), neurofibrillary tangles (NFT), and neuronal loss [1]. Senile plaques are largely found in the hippocampus, amygdala, and neocortex in the brain of AD patients and consist of dystrophic neurites [2]. The receptors for advanced glycation end-products (RAGE) are considered to be playing an important role in neurodegenerative physiological changes, which further progress toward AD. This receptor is thought to be a promoting factor for synaptic and neuronal circuit dysfunction, both of which are the material structure of cognition, as well as the physiological and pathological basis of cognition [3].

RAGE plays a significant role in other physiological and pathological progressions as it can bind to a large number of ligands. And AGEs are one of the crucial ligands of RAGE. Advanced glycation end-products (AGEs) are modified, non-functioning proteins or lipids which are non-enzymatically glycated and oxidized after exposure to the aldose sugars. More than 30 years of research is connoting that AGEs have been interlinked with aging and neurodegenerative diseases, including $\mathrm{AD}$ [4-7]. AGEs unravel many of the neuropathological and biochemical features of $\mathrm{AD}$ such as glial induction of oxidative stress, extensive protein crosslinking, and neuronal cell death [8]. AGEs are mainly derived from two sources, from dietary intake and internally produced in the body [9]. RAGE is a $35 \mathrm{kD}$ transmembrane receptor which is the receptor for AGEs and is categorized to the immunoglobulin superfamily $[10,11]$. Two isoforms of RAGE can be found, of which one is membrane-bound form and the other one is a soluble form known as mRAGE and sRAGE respectively [3]. RAGE is involved in Alzheimer's through amyloid-beta production, $A \beta$ clearance, synaptic damage, and neuronal circuit dysfunction. Additionally, RAGE-A $\beta$ interaction controls the bi-directional crosslink between peripheral and central systems in the brain [12].

There is an increasing amount of evidence that shows that AGEs promote aging, neurodegeneration, cognitive impairment, and other vascular complications through AGE-RAGE interaction and pathways induced by the process [13]. Cardiovascular diseases (CVD), obesity, diabetes, hypercholesterolemia, renal failure, traumatic brain injury, and different inflammatory factors are directly or indirectly related to the progression of $\mathrm{AD}$ via AGEs-RAGE reactions and/or RAGE-ligands-mediated cytotoxicity. It is not clear how $\mathrm{AD}$ and diabetes are interlinked precisely but there are several from which it is evident that diabetes and diabetes-related neuropathy are risk factors for $\mathrm{AD}$ and dementia. Excessive production of AGEs due to hyperglycemia, impaired insulin growth factor, and oxidative stress are considered to be crucial factors to the onset of $\mathrm{AD}$ [14].
In our present study, a literature search was carried out to retrieve the relevant articles, mainly from electronic databases such as Google Scholar (https://scholar. google.com/), Science Direct (https://www.sciencedirect. com/), and PubMed (https://pubmed.ncbi.nlm.nih.gov/). We executed our search using the following terms: Alzheimer's; AGEs; RAGE; RAGE in Alzheimer's; AGEs in Alzheimer's; RAGE in diabetes; RAGE related pathways of CVD; RAGE in hypertension; RAGE and RAS system; RAGE and oxidative stress with the timeframe from 2006 to 2021. We also considered some quality articles outside the aforesaid timeframe to support the current information. Original research articles, review articles, commentaries, and letters to the editor were included whereas poster papers, advertisements, thesis works, preprints, and published studies in non-English languages were excluded. Our main focus was to study the common factors and targets of $\mathrm{AD}$, diabetes, and CVD which is mainly oxidative stress and cellular inflammation related to RAGE and its interaction with AGEs and other ligands. We further studied the possible mechanisms as well as pathways related to these disorders and tried to establish an association among them. The overview of the relationships among the aforementioned diseases is represented in Fig. 1.

\section{Alzheimer disease and roles of RAGE RAGE in senile plaque formation}

It was proposed that overproduction of $A \beta$ and/or failure of $A \beta$ clearance and deposition of $A \beta$ into the brain are the cause of SP formation in the AD brain. It also showed the importance of RAGE in the production and clearance of $A \beta$ [3]. The equilibrium of synthesis, reuptake, and clearance of $A \beta$ put a steady-state level in the brain but any factor that hampers this equilibrium or causes the failure of clearance effectively can cause the accumulation of $A \beta$, which further progress to the formation of plaques [15]. Among the several mechanisms of $A \beta$ clearance, the low-density lipoprotein receptor-related protein 1(LRP-1) and RAGE acts on the A $\beta$ transport system. It is known that RAGE acts as the primary transporter of $A \beta$ into the brain whereas LRP- 1 transports $A \beta$ out of the brain. The tight junction is identified as the basic structure of the blood-brain barrier (BBB) and RAGEmediated $A \beta$ cytotoxicity to the brain microvascular endothelial cells. This results in the damage of BBB structural integrity. The disruption of tight junction proteins and induction of $\mathrm{BBB}$ integrity breakage are regulated by $A \beta-R A G E$ interactions via $\mathrm{Ca}^{2+}$-calcineurin $(\mathrm{CaN})$ pathway. On the other hand, disrupted micro-vessels coexist with $A \beta$ plaque-deposited areas, elevated RAGE expression, and enhanced matrix metalloproteases (MMPs) secretion in the brains of 5XFAD mice. This indicated 


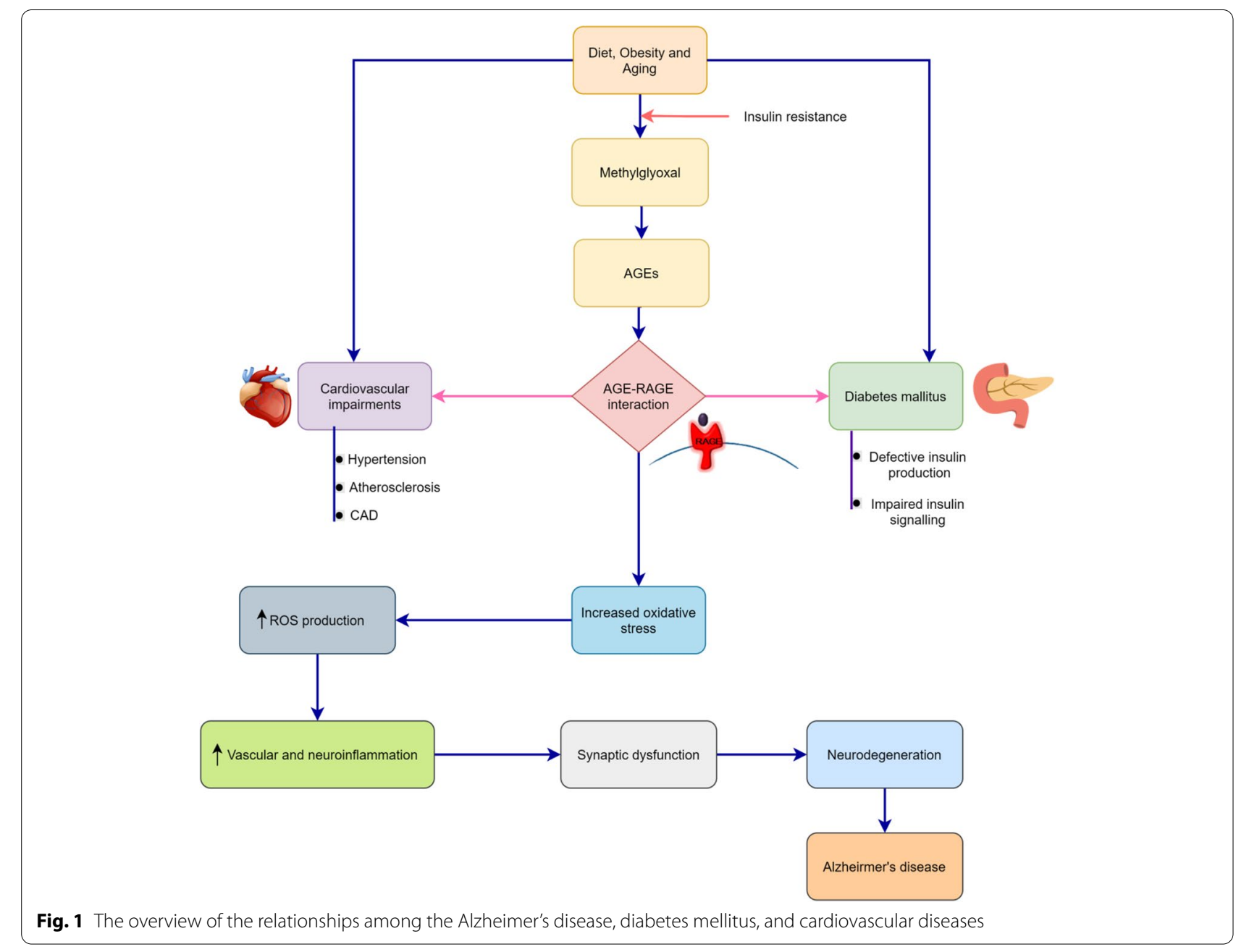

a potential molecular pathway underlying $A \beta-R A G E-$ induced breakage of BBB integrity [3]. An in vivo study demonstrated that $\mathrm{AD}$ is associated with significant changes in the relative distribution of RAGE and LRP-1 receptors at the $\mathrm{BBB}$ in the human hippocampus. The hypothesis that vascular amyloid deposition increases within the brains of AD patients is well supported by this study [16].

\section{RAGE information of neurofibrillary tangles}

Neurofibrillary tangles (NFTs) are one of the important markers of $\mathrm{AD}$ [17]. In the AD brain, the NFT is formed due to the accumulation of tau protein which is hyperphosphorylated and aggregated in neuron-forming helical filaments. This ultimately results in the loss of microtubule-binding capacity and proceeds toward neurodegeneration [18]. One of the preliminary changes in the tangle formation process is the deposition of irregularly phosphorylated tau protein in the AD brain [19]. Tau is generally found in neurons and is a heat-stable protein possessing six isoforms containing 352 to 441 amino acids functioning in the assembly and stabilization of microtubules [20]. Normally, tau protein possesses a low tendency to aggregate and two phosphates are present in each molecule. However, abnormal phosphorylation of tau induces the accumulation of insoluble tau aggregates and demonstrated the presence of eight phosphates per molecule of tau in the AD brain [21]. Hyperphosphorylation at the specific site of tau (e.g., S262 or S214) results in detachment of tau from the microtubule and as a consequence microtubule disappears from the neuron. Intracellular transport is hampered, which causes degeneration of neurons [22].

AGEs can instigate tau hyper-phosphorylation which cause damage to synaptic protein, impair long-term potentiation (LTP) and deteriorate memory through RAGE/GSK-3 activation [23]. Both abnormally tau hyperphosphorylation and RAGE upregulation are engaged in the progression of neurodegeneration [24]. At multiple AD-related sites, methylglyoxal (MG) can promote 
hyperphosphorylation of tau in the neuroblastoma $2 \mathrm{a}$ cells while maintaining regular cell viability. Interestingly, MG increases the level of AGEs as well as RAGE and also activates the glycogen synthesis kinase- $3 \beta$ (GSK-3 $\beta$ ) and p38 MARK. These data are evident for correlating the induction of tau hyper-phosphorylation with upregulation of RAGE [25]. Another study involving astrocyte-derived S100B protein demonstrated that S100B stimulates JNK (c-Jun N-terminal kinases) phosphorylation through RAGE which then increases the expression of Dickoff- 1 . This in turn raises GSK-3 $\beta$ phosphorylation and catenin degradation which causes canonical Wnt pathway disruption and tau protein hyper-phosphorylation [26]. A study using PPAR $\beta / \delta$-null mice also demonstrated the presence of upregulated level of RAGE and tau hyper-phosphorylation [27].

\section{RAGE and its role in oxidative stress}

Oxidative stress is induced due to an imbalance of free radical production and detoxification [8]. In the body, when the anti-oxidant system cannot counterattack the free radicals or oxidative species sufficiently, it produces oxidative stress. The oxidative stress associated with AD includes AGEs, nitration, lipid peroxidation adduction products, carbonyl-modified neurofilament protein, and free carbonyls [28]. Previous studies showed that the significance of oxidative stress is associated with the increase of $A \beta$ and NFT in AD [29]. The hyperphosphorylated tau protein of NFT is linked with oxidation via microtubule-associated protein kinase pathway and activation of the transcription factor, NF- $\mathrm{kB}$ (nuclear factor kappa-light-chain-enhancer of activated $B$ cells) [30]. NFT in AD is significantly associated with oxidative damage. The production of oxidative species includes so many pathways and RAGE is playing a significant role as the AGEs, as well as $A \beta$, activates RAGE and the class A1 scavenger receptors (SR-A1) to increase reactive oxygen species (ROS) production [28].

\section{RAGE-AGEs associated inflammation and cell injury preceding the $A D$}

AGEs-RAGE interaction is a potential trigger for causing oxidative stress and inflammation which also accelerates the aging process, consequently enhancing cognitive decline and impairment [31,32]. It is well evident that RAGEs can also bind with other ligands and trigger several signaling pathways which then results in chronic inflammation and cellular stress [33]. RAGE is responsible for the formation of ROS and induction of transcription factor NF-kB which increases the expression of various inflammatory cytokines and upregulation of RAGE itself [34, 35]. The two most hallmark pathologies of $\mathrm{AD}$ are NFT and SP, which are produced by the enhanced oxidative stress and inflammation via RAGEAGEs or RAGE-ligand interactions. RAGE plays a crucial part in promoting oxidative stress, mitochondrial dysfunction, disrupted energy metabolism, and inflammation thus increasing synaptic dysfunction, promoting the pathogenesis of $A \beta$ and tau hyper-phosphorylation. It is evident from different animal and human model studies that the concentration of AGEs is higher in Alzheimer's patients compared to the normal brain [4]. The pathogenesis of AGE is upregulated by some processes like diabetes mellitus (DM) or excessive blood glucose, crosslinking of long-lived proteins with sugars, generation of methoxyl species, oxidative stress, ROS, and inflammatory stimuli [3]. Some previous studies corroborated that AGEs are involved in an unending cycle of inflammation, cellular stress, and ROS production. AGEs may be associated with increased ROS production via multiple mechanisms, along with AGEs-RAGE ligation, decreased superoxide dismutase (SOD) and catalase activities, depleting glutathione stores, and activating protein kinase $C[36,37]$. AGEs-RAGE ligation increases $A \beta$ production which then interacts with more RAGEs. Firstly, $A \beta$ production is increased and accumulates amyloid plaques via AGEs-RAGE ligation. Secondly, $A \beta$ activates the inflammatory state in the microglia and astrocytes cells of the brain which promotes further inflammation through various inflammatory factors. Thirdly, these inflammatory factors cause neurodegeneration and the death of neurons $[5,38-41]$.

Upregulation of RAGE increases the transportation of $A \beta$ across the BBB into the brain, thereby reduces cerebral blood flow, and causes neuronal damage. Scientific evidence supports RAGE playing an important role in activating a positive feedback loop of A $\beta$-RAGE interaction. This promotes more cellular stress, and neuroinflammation which then increases $A \beta$ production and $A \beta$ cytotoxicity $[42,43]$. RAGE increases $A \beta$ production and neuro-inflammation in glial cells of the brain via various pathways like mitogen-activated protein kinase (MAPK), peroxisome proliferator-activated receptor- $\gamma$ (PPAR- $\gamma$ ), transcriptional signaling cascade NF- $\mathrm{kB}$, which further releases different inflammatory factors including interleukin-1 beta(IL-1 $\beta$ ), interleukin 1 (IL-1), interleukin 6 (IL-6), plasminogen activator inhibitor-1 (PAI-1), tumor necrosis factor- $\alpha$ (TNF- $\alpha$ ), monocyte chemoattractant protein-1(MCP-1), intercellular adhesion molecule-1 (ICAM-1), vascular cell adhesion molecule-1 (VCAM-1) that are all involved in the pathogenesis of AD [44]. Normally microglial cells act as a protective factor in response to any stress or inflammation in the brain. However, with the increased level of $A \beta$ production, this becomes more inflammatory and their activity diminishes with the progression of senile plaques. When the $A \beta$ level increases in 
the microglial cells, it releases cytokines which activate $\beta$ secretases (BACE1) and $\gamma$ secretases to clear the $A \beta$ but the inflammatory factors promote further $A \beta$ proliferation and activation of microglial damage [45-47]. Additionally, from the animal studies, it is evident that in the astrocyte cells the NF- $\mathrm{kB}$ pathway was upregulated by the RAGE and increased amyloid plaques. This releases TNF- $\alpha$, IL-B, COX2 cytokines, and directly stimulates expression of BACE1 and therefore increases the conversion of amyloid precursor protein (APP) to toxic $\gamma$ secretases. Thus, the reactive astrocytes are responsible for the $A \beta$ accumulation and neurotoxicity [48-50].

\section{RAGE-mediated pathways of type 2 diabetes mellitus and AD}

People are quite familiar with type 1 and type 2 diabetes. However, there has been a new type of diabetes which is type 3 diabetes or "Diabetes of the Brain." Disease progression and symptoms of $\mathrm{AD}$ and type 3 diabetes are similar to such extent that $\mathrm{AD}$ is sometimes termed as type 3 diabetes albeit controversial in the use of this term. Difficulty in remembering recent events, mood and behavioral changes, linguistic problems, loss of motivation, and spirit following cognitive impairment are some common symptoms in both cases [51-54]. There are shreds of evidence from the human study as well as from the animal model study which justified AD as type 3 diabetes. From these in vivo, in vitro, and post mortem studies of human brains, it is demonstrated that insulin resistance in the brain and impaired insulin-like growth factor signaling are common main causes of vascular damage and dementia [55].

Cognitive dysfunction in long-term diabetes patients is a less explored topic. Obesity, hyperlipidemia, and diabetes are some of the variable risk factors for $\mathrm{AD}$. AGE products produced by hyperglycemia and RAGE play an important role in both AD and DM [56]. AGEsRAGE interaction is associated with vascular aging and complications like DM, insulin resistance, AD, cancer growth, and metastasis by provoking oxidative stress, cell inflammation, and other pathways [57]. Kong et al. in their recent research study depicted the mechanisms of RAGE as the common target between AD and DM and interlinked DM to AD through RAGE [14]. A large number of studies, e.g., the Rotterdam study, clinical trials, and cellular imaging have been carried out to identify and demonstrate the link between type 2 diabetes mellitus (T2DM) related vascular complications (e.g., polyneuropathy, dementia) and $\mathrm{AD}$-associated cognitive dysfunction. Long-term hyperglycemia enhances AGEs production and then interacts with RAGE. As a consequence, there is an increase in the ROS production of the vascular cells, e.g., endothelial cells, smooth muscle cells, and mononuclear phagocytes. These are also involved in diabetes-induced atherosclerosis, nephropathy, and retinopathy. Therefore, there is an elevation in the vascular inflammation and AD pathogenesis [58-60].

Several studies showed insulin resistance, impaired insulin receptor, insulin-like growth factor, and glucose toxicity might be the key features through which T2DM influences AD [58]. Aging, hypercholesterolemia, atherosclerosis, hypertension, obesity, and inflammation are some additional risk factors related to both T2DM and AD [61]. Defective insulin receptor signaling in T2DM patients cause $A \beta$ toxicity in the neurons which could eventually lead to $A \beta$-induced oxidative stress in cells. Additionally, an increased amount of $A \beta$ interacting with the neuronal RAGE causes free radical-mediated cellular oxidative stress and activation of transcription factor NF- $\mathrm{kB}$, resulting in an increase in the expression of various inflammatory cytokines. Lue et al. discussed different mechanisms of T2DM and $\mathrm{AD}$ as well as the probable synergism of these two diseases when occurring in the same patient. There is strong evidence that supports inflammation as the key feature in $A D$ and T2DM patients. In both $\mathrm{AD}$ and T2DM, there is an elevated level of inflammatory mediators and markers like cytokines (e.g., IL-1 $\beta$, IL-6, TNF- $\alpha$ ), chemokines (e.g., IL-8, MCP-1), growth factor (G-CSF), and S100B in the affected brain regions and pancreas of $\mathrm{AD}$ and $\mathrm{T} 2 \mathrm{DM}$ patients respectively. The involvement of some receptors and ligands, e.g., macrophage scavenger receptors (MSR-A, MSR-B), toll-like receptors (TLR2, TLR4), and advanced glycation end-products (RAGE; AGEs) were found in both DM and AD [58].

The latest evidence showed that RAGE and its ligands, S100B and HMG-1, induced oxidative stress and inflammation are involved in cell injury and apoptotic cell death in pancreatic islet cells via NADPH oxidase. Inhibition of AGEs production and RAGE-associated inflammatory mechanisms are also responsible [62]. NADPH oxidase stimulation in occurrence with free fatty acids and high glucose level escalates the proliferation of TLR2 and TLR4 via protein kinase $C$. This results in the induction of inflammatory response through activation of NF- $\mathrm{KB}$. TLR4 in pancreatic cells is upregulated and interferoninducible protein-10 (IP-10), a chemokine ligand activates the receptor leading to cell apoptosis of islets cells. In developing T2DM therapeutics, enhancing soluble RAGE (sRAGE)-related mechanisms were thought to be effective as sRAGE antagonizes the RAGE functions both in the brain and periphery. sRAGE also has a protective function against inflammation. As in T2DM, there is a deficiency of sRAGE. Therefore, molecules having the ability to block RAGE or increase the function of sRAGE 
can be potential therapeutics for both T2DM and AD [58].

\section{RAGE in cardiovascular disease: pathways leading to AD}

Different studies showed that midlife hypertension is associated with $\mathrm{AD}$. Amyloid beta $(\mathrm{A} \beta)$, the hallmark of $\mathrm{AD}$, was found in the heart and the brain of Alzheimer's patients. However, from different animal model studies and human autopsy, it is evident that aging, atherosclerosis, hypercholesterolemia, heart failure, myocardial infarction, impaired renin-angiotensin system, etc., are all potential risk factors for both $\mathrm{AD}$ and CVD and different anti-hypertensive agents and other pharmacological agents for heart diseases are being considered to be therapeutic interventions for $\mathrm{AD}$ [63]. Blood vessels located in the brain help to transport essential nutrients and also eliminate the waste products from the central nervous system (CNS) [64]. The interrelation between the health of the brain and the overall health of the heart and blood vessels is becoming increasingly evident from the current studies. Oxygen and nutrient-rich blood are required for the brain to function properly and a healthy heart ensures enough blood is pumped and circulated through the blood vessels. Many factors, like smoking, obesity, diabetes, and high cholesterol which are responsible for the risk of CVD, are well connected to the increased risk of dementia. Mid-life hypertension is also associated as a risk factor for late-life dementia [65]. However, coronary artery bypass surgery (CABG), atrial fibrillation, congestive heart failure (CHF), coronary artery disease (CAD), stroke, and myocardial ischemia are all linked with the progression of dementia and $\mathrm{AD}$ [66]. CAD and other vascular diseases result in the accumulation of SP and NFT in the brain, which is the main cause of AD [67]. In CAD, AGE as well as its receptor RAGE plays a vital role in the formation of atherosclerosis. RAGE-AGE interactions are atherogenic and an elevated level of AGE-RAGE stress causes progression of CAD [68].

\section{Hypertension}

Recent studies suggested that hypertension is associated with AD. Hypertension plays a key role in brain pathologies such as stroke and dementia [69]. From population-based studies, it was evident that both high systolic blood pressures (SBP) and diastolic blood pressures (DBP) can accelerate the onset of clinical AD by 10 to 15 years. Almost 4000 Japanese American men were examined in the Honolulu-Asia aging study during 1965-1971 to verify the findings and in 1991 re-examined for dementia. This study demonstrated that $\mathrm{AD}$ and vascular dementia can be developed 20-26 years later after being diagnosed with a high SBP or DBP. Further research from the above aging study reported that lower brain weight and increased amount of SP in both neocortex and hippocampus were associated with midlife SBP of $160 \mathrm{mmHg}$ or above. In the hippocampus, elevated DBP of $95 \mathrm{mmHg}$ or above was associated with increasing NFT. These suggested that hypertension appears decades before the onset of $\mathrm{AD}$ and is immensely related to the progression of $\mathrm{AD}$ [70]. Risk factors for hypertension such as high salt intake, overweight, stress, diabetes, and the impaired renin-angiotensin system can be related to the onset of $\mathrm{AD}$. Hypertension impairs cerebral blood flow (CBF) and increases intracranial pressure [69]. A number of studies suggested the cerebral amyloid angiopathy (CAA) in association with chronic hypertension promotes atherosclerosis in cerebral arteries and causes white matter lesions, intracranial hemorrhage, and ischemic stroke [71-73]. Chronic hypertension changes the structure and function of cerebral blood vessels and disrupts the balance between CNS and periphery maintained by BBB. As a result, an increased amount of $A \beta$ interacts with the RAGE receptors and causes $A \beta$ accumulation and neurodegeneration. Normally, RAGEs are found in the BBB for $A \beta$ transportation. However, from transgenic murine models, it is reported that RAGE expression is upregulated in the hypertensive state. This accumulates $A \beta$, initiates an immune response, promote inflammation, and cognitive dysfunction [74].

\section{Atherosclerosis and coronary artery disease (CAD)}

The atherosclerotic arterial disease can be manifested clinically as CVD which is accountable for almost $70 \%$ of all causes of death in patients with T2DM [75]. Atherosclerosis and $\mathrm{AD}$ are two significant life-threatening conditions and when act together synergistically can be fatal and dangerous to public health. Atherosclerosis is the clogging and narrowing of blood vessels by plaques, and fatty deposits usually cholesterol. From the early 1990s, atherosclerosis is associated with the pathogenesis of dementia. Risk factors of atherosclerosis include diabetes, hypercholesterolemia, aging, and hyperhomocysteinemia [76]. There are a lot of studies regarding the link between $\mathrm{AD}$ and atherosclerosis. Lately, investigators found that $77 \%$ of AD subjects in a large cohort of 1000 cases with microscopic neuropathological data had an apparent circle of Willis atherosclerosis at a significantly higher rate than that of normal subjects or subjects with non-AD disease [77]. Furthermore, a study of 4371 stroke-free middle-aged patients found that atherosclerosis can predict future cognitive impairment levels even after 7 years [78]. Then in a 10-year fold-up, a longitudinal study of population-based subjects depicted that the thickness of intima-media was implicated with a higher risk of developing cognitive impairment [79]. Also, some 
studies show that apolipoprotein E4 or APOE4 is a prominent genetic risk factor of dementia as well as $A D$ which increases $\mathrm{BBB}$ damage, CAA, and fibrinogen deposits in the human brain [80]. Overexpression of APOE4 causes increased circulating levels of cholesterol which results in coronary artery disease. APOE4 and increased cholesterol concentration lead to elevated levels of oxidized low-density lipoproteins (LDL), which causes neuronal cell death once reached in the brain [81]. Atherosclerosis causes reduced blood flow and blood volume or oligemia which can lead to overexpression and enhanced processing of $A \beta$ precursor protein (APP). APP promotes $A \beta$ accumulation in the brain and causes inflammation and further neuronal injury [76].

\section{Renin-angiotensin system}

The Renin-angiotensin system (RAS) can be defined as a hormonal system that maintains the regulation of body water and plays an important role in the cardiovascular system where angiotensin I is a main component or effector. RAS exerts vasoconstrictive properties by Ang II which acts on the angiotensin type 1 receptor (AT1R) and angiotensin type 2 receptor (AT2R). Kidneys produce the enzyme renin which produces angiotensin I (Ang I) by acting on the angiotensinogen. After that, Ang I is converted into angiotensin II (Ang II) by the angiotensin-converting enzyme (ACE). Angiotensin promotes aldosterone secretion, vasoconstriction, sodium retention, activation of the sympathetic nervous system. It also increases cytosolic-free calcium, ROS production, and subsequently stimulates a series of other possible atherogenic processes including hyperplasia, hypertrophy of vascular smooth muscle cells [82, 83]. An elevated amount of angiotensin 2 in the brain can impair memory functions but angiotensin 2 receptor blockers or antagonists have improved the cognitive functions in mice models [84-87]. Ang II causes brain inflammation by oxidative stress via the AT1R while AT2R signaling has a beneficial effect on learning and memory. Angiotensin receptor blockers (ARBs) inhibit mainly AT1 receptor signaling which increases the potentially effective pathway of AT2 receptor toward improved memory functions [88]. Now, there is increasing numbers of evidence that the RAS system, AGEs, and the AGE-RAGE system interact with each other. It was suggested that AGE-RAGE binding stimulates intracellular calcium of vascular smooth muscle and other cells which can be mediated by ROS $[89,90]$. Sprague Dawley rats infused with AGE-modified rat serum albumin increased renal expression of angiotensin, ACE, and angiotensin receptor type 1 and also increased renal ACE activity. This study further showed glomerular and tubular cell growth and AGE accumulation. While an angiotensin receptor type
$1\left(\mathrm{AT}_{1} \mathrm{R}\right)$ blocker has antagonized these changes. A study conducted by Kehoe et al. showed increased accumulation and deposition of $A \beta$ peptides by Ang II along with ACE in AD animal models [91]. Ang II also promotes cerebrovascular dysfunction and micro-vascular amyloid deposition which then, in turn, accelerate $\mathrm{AD}$ symptoms and outcomes [92]. Fukami et al. showed that AGEsRAGEs interactions increase ROS production that stimulates Ang II level in vascular and other cells. In another animal-model study of the rat kidney, oxidative stress increased the activity of ACE via oxidation of sulfhydryl (-SH) groups [93, 94]. AGE-RAGE interactions involved with reactive oxygen species, NF- $\mathrm{kB}$, and the RAS system cause AGE-induced DNA damage to different cell types [95]. There are also further animal modal studies and human clinical studies to prove the correlation among the AGEs, RAGEs, RAS systems which are involved significantly in vascular diseases like hypertension, atherosclerosis, and diabetes, which are potential risk factors for the onset of $\mathrm{AD}[88,96]$.

\section{Conclusions}

$\mathrm{AD}$ is the most prominent cause of dementia worldwide and miserably there has been no innovative therapy available for AD. RAGE plays an important mediator role in the progression of $\mathrm{AD}$. In the early stages of Alzheimer's disease, the immune system promotes the clearance of amyloid peptides. However, as the disease progresses, activation of the innate immune system along with the inability to secrete toxic $A \beta$ peptides can lead to chronic inflammation in the brain. The presence of RAGE for several cell types contributing to the potential for neuronal dysfunction in $\mathrm{AD}$, including blood-brain barrier cells, microglia, astrocytes, and neurons. RAGE-mediated $A \beta$ formation, tau phosphorylation, and other inflammatory pathways enhance $\mathrm{AD}$ development. $\mathrm{AD}$ is linked with progression with several cardiovascular diseases like hypertension, CAD, CHF, and stroke. RAGE interacts with the RAS systems which may influence ROS production and the NF- $\mathrm{KB}$ signaling pathway to cause cell damage. Also, RAGE and RAS systems influence the pathophysiology of diabetic complications such as retinopathy, nephropathy, and atherosclerosis. New compound targeting RAGE expression, RAGE-ligand interaction, AGE formation, and upregulation of sRAGE can be a potential therapeutic agent to prevent or slow down the development of $\mathrm{AD}$. Further investigations are needed to find out the mechanistic role of RAGE and its association with different metabolic disorders. 


\section{Abbreviations}

AD: Alzheimer's disease; SP: Senile plaques; NFT: Neurofibrillary tangles; RAGE: Receptors for advanced glycation end-products; AGE: Advanced glycation end-products; CVD: Cardiovascular diseases; AB: Amyloid beta; BBB: Bloodbrain barrier; MMPs: Matrix metalloproteases; LRP-1: Lipoprotein receptor-

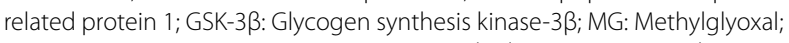
ROS: Reactive oxygen species; SOD: Superoxide dismutase; DM: Diabetes mellitus; NF-kB: Nuclear factor kappa-light-chain enhancer of activated B cells; SR-A1: Class A1 scavenger receptors; MAPK: Mitogen-activated protein kinase; PPAR- $\gamma$ : Peroxisome proliferator-activated receptor- $\gamma$; IL: Interleukin; PAI-1: Plasminogen activator inhibitor-1; TNF-a: Tumor necrosis factor- $a_{\text {; }}$ MCP-1: Monocyte chemoattractant protein-1; ICAM-1: Intercellular adhesion molecule-1; VCAM-1: Vascular cell adhesion molecule-1; APP: Amyloid precursor protein; T2DM: Type 2 diabetes mellitus; MCR: Macrophage scavenger receptors; TLR: Toll-like receptors; sRAGE: Soluble RAGE; CNS: Central nervous system; CABS: Coronary artery bypass surgery; CHF: Congestive heart failure; CAD: Coronary artery disease; SBP: Systolic blood pressures; DBP: Diastolic blood pressures; CBF: Cerebral blood flow; CAA: Cerebral amyloid angiopathy; LDL: Low-density lipoproteins; APP: A $\beta$ precursor protein; RAS: Renin-Angiotensin system; AT1R: Angiotensin type 1 receptor; AT2R: Angiotensin type 2 receptor; Ang I: Angiotensin I; Ang II: Angiotensin II; ACE: Angiotensin-converting enzyme; ARB: Angiotensin receptor blockers.

\section{Acknowledgements}

The authors are thankful to Ahmed Rakib, Department of Pharmaceutical Sciences, College of Pharmacy, The University of Tennessee Health Science Center, 881 Madison Ave, Memphis, TN, 38163, USA, for his support throughout the review work

\section{Authors' contributions}

AC: conception, design, writing —original draft preparation, writing - review and editing; SAS: conception, design, formal analysis, project administration, writing - review and editing, supervision; KKSM: conception, design, formal analysis, investigation, writing - original draft preparation. All authors read and approved the final manuscript.

\section{Funding}

Not applicable.

\section{Availability of data and materials}

Not applicable.

\section{Declarations}

Ethics approval and consent to participate

Not applicable.

\section{Consent for publication}

Not applicable.

\section{Competing interests}

The authors declare that they have no competing interests.

Received: 12 October 2021 Accepted: 24 October 2021

Published online: 13 November 2021

\section{References}

1. Martin JB (1999) Molecular basis of the neurodegenerative disorders. $N$ Engl J Med 340:1970-1980. https://doi.org/10.1056/nejm19990624340 2507

2. Price DL, Sisodia SS (1998) Mutant genes in familial Alzheimer's disease and transgenic models. Annu Rev Neurosci 21:479-505. https://doi.org/ 10.1146/annurev.neuro.21.1.479

3. Cai Z, Liu N, Wang C, Qin B, Zhou Y, Xiao M, Chang L, Yan L, Zhao B (2016) Role of RAGE in Alzheimer's disease. Cell Mol Neurobiol 36:483-495. https://doi.org/10.1007/s10571-015-0233-3
4. Takeuchi M, Yamagishi SI (2008) Possible involvement of advanced glycation end-products (AGEs) in the pathogenesis of Alzheimer's disease. Curr Pharm Des 14:973-978. https://doi.org/10.2174/138161208784139693

5. Galasko D, Bell J, Mancuso JY, Kupiec JW, Sabbagh MN, van Dyck C, Thomas RG, Aisen PS (2014) Clinical trial of an inhibitor of RAGE-A interactions in Alzheimer disease. Neurology 82:1536-1542. https://doi. org/10.1212/WNL.0000000000000364

6. Kuhla A, Ludwig SC, Kuhla B, Münch G, Vollmar B (2015) Advanced glycation end products are mitogenic signals and trigger cell cycle reentry of neurons in Alzheimer's disease brain. Neurobiol Aging 36:753-761. https://doi.org/10.1016/j.neurobiolaging.2014.09.025

7. Perrone L, Grant WB (2015) Observational and ecological studies of dietary advanced glycation end products in national diets and Alzheimer's disease incidence and prevalence. J Alzheimers Dis 45:965-979. https:// doi.org/10.3233/JAD-140720

8. Srikanth V, Maczurek A, Phan T, Steele M, Westcott B, Juskiw D, Münch G (2011) Advanced glycation endproducts and their receptor RAGE in Alzheimer's disease. Neurobiol Aging 32:763-777. https://doi.org/10.1016/j. neurobiolaging.2009.04.016

9. Semba RD, Gebauer SK, Baer DJ, Sun K, Turner R, Silber HA, Talegawkar S, Ferrucci L, Novotny JA (2014) Dietary intake of advanced glycation end products did not affect endothelial function and inflammation in healthy adults in a randomized controlled trial. J Nutr 144:1037-1042. https://doi. org/10.3945/jn.113.189480

10. Wautier M, Tessier F, Wautier J (2014) Advanced glycation end products: a risk factor for human health. Ann Pharm Fr 72:400-408. https://doi.org/ 10.1016/j.pharma.2014.05.002

11. Yu S, Wong C, Szeto C, Li E, Cai Z, Tam L (2015) Members of the receptor for advanced glycation end products axis as potential therapeutic targets in patients with lupus nephritis. Lupus 24:675-686. https://doi.org/10. 1177/0961203314559631

12. Chellappa RC, Palanisamy R, Swaminathan K (2020) RAGE isoforms, its ligands and their role in pathophysiology of Alzheimer's disease. Curr Alzheimer Res 17:1262-1279. https://doi.org/10.2174/156720501866621 0218164246

13. Xue J, Ray R, Singer D, Böhme D, Burz DS, Rai V, Hoffmann R, Shekhtman A (2014) The receptor for advanced glycation end products (RAGE) specifically recognizes methylglyoxal-derived ages. Biochemistry 53:3327-3335. https://doi.org/10.1021/bi500046t

14. Kong Y, Wang F, Wang J, Liu C, Zhou Y, Xu Z, Zhang C, Sun B, Guan Y (2020) Pathological mechanisms linking diabetes mellitus and Alzheimer's disease: the receptor for advanced glycation end products (RAGE). Front Aging Neurosci 12:217. https://doi.org/10.3389/fnagi.2020.00217

15. Yoon SS, Jo SA (2012) Mechanisms of amyloid- $\beta$ peptide clearance: potential therapeutic targets for Alzheimer's disease. Biomol Ther 20:245-255. https://doi.org/10.4062/biomolther.2012.20.3.245

16. Donahue JE, Flaherty SL, Johanson CE, Duncan JA 3rd, Silverberg GD, Miller MC, Tavares R, Yang W, Wu Q, Sabo E, Hovanesian V, Stopa EG (2006) RAGE, LRP-1, and amyloid-beta protein in Alzheimer's disease. Acta Neuropathol 112:405-415. https://doi.org/10.1007/s00401-006-0115-3

17. Ashe KH, Zahs KR (2010) Probing the biology of Alzheimer's disease in mice. Neuron 66:631-645. https://doi.org/10.1016/j.neuron.2010.04.031

18. Šerý O, Povová J, Mišek I, Pešák L, Janout V (2013) Molecular mechanisms of neuropathological changes in Alzheimer's disease: a review. Folia Neuropathol 51:1-9. https://doi.org/10.5114/fn.2013.34190

19. Bancher C, Brunner C, Lassmann H, Budka H, Jellinger K, Wiche G, Seitelberger F, Grundke-lqbal I, labal K, Wisniewski H (1989) Accumulation of abnormally phosphorylated $\tau$ precedes the formation of neurofibrillary tangles in Alzheimer's disease. Brain Res 477:90-99. https://doi.org/10. 1016/0006-8993(89)91396-6

20. Sun J-H, Yu J-T, Tan L (2015) The role of cholesterol metabolism in Alzheimer's disease. Mol Neurobiol 51:947-965. https://doi.org/10.1007/ s12035-014-8749-y

21. Gulisano W, Maugeri D, Baltrons MA, Fà M, Amato A, Palmeri A, D'Adamio L, Grassi C, Devanand D, Honig LS (2018) Role of amyloid- $\beta$ and tau proteins in Alzheimer's disease: confuting the amyloid cascade. J Alzheimers Dis 64:S611-S631. https://doi.org/10.3233/JAD-179935

22. Bilen J, Liu N, Burnett BG, Pittman RN, Bonini NM (2006) Microrna pathways modulate polyglutamine-induced neurodegeneration. Mol Cell 24:157-163. https://doi.org/10.1016/j.molcel.2006.07.030 
23. Li X-H, Lv B-L, Xie J-Z, Liu J, Zhou X-W, Wang J-Z (2012) AGEs induce Alzheimer-like tau pathology and memory deficit via RAGE-mediated GSK-3 activation. Neurobiol Aging 33:1400-1410. https://doi.org/10. 1016/j.neurobiolaging.2011.02.003

24. Gasparotto J, Senger MR, Kunzler A et al (2015) Increased tau phosphorylation and receptor for advanced glycation endproducts (RAGE) in the brain of mice infected with Leishmania amazonensis. Brain Behav Immun 43:37-45. https://doi.org/10.1016/j.bbi.2014.06.204

25. Li XH, Xie JZ, Jiang X, Lv BL, Cheng XS, Du LL, Zhang JY, Wang JZ, Zhou XW (2012) Methylglyoxal induces tau hyperphosphorylation via promoting AGEs formation. Neuromol Med 14:338-348. https://doi.org/10.1007/ s12017-012-8191-0

26. Esposito G, Scuderi C, Lu J, Savani C, De Filippis D, luvone T, Steardo L $\mathrm{Jr}$, Sheen V, Steardo L (2008) S100B induces tau protein hyperphosphorylation via Dickopff-1 up-regulation and disrupts the Wnt pathway in human neural stem cells. J Cell Mol Med 12:914-927. https://doi.org/10. 1111/j.1582-4934.2007.00159.x

27. Barroso E, del Valle J, Porquet D, Santos AMV, Salvadó L, RodríguezRodríguez R, Gutiérrez P, Anglada-Huguet M, Alberch J, Camins A (2013) Tau hyperphosphorylation and increased BACE1 and RAGE levels in the cortex of PPAR $\beta / \delta$-null mice. Biochim Biophys Acta Mol Basis Dis 1832:1241-1248. https://doi.org/10.1016/j.bbadis.2013.03.006

28. Smith MA, Rottkamp CA, Nunomura A, Raina AK, Perry G (2000) Oxidative stress in Alzheimer's disease. Biochim Biophys Acta Mol Basis Dis 1502:139-144. https://doi.org/10.1016/S0925-4439(00)00040-5

29. Christen Y (2000) Oxidative stress and Alzheimer disease. Am J Clin Nutr 71:621S-629S. https://doi.org/10.1093/ajen/71.2.621s

30. Markesbery WR (1999) The role of oxidative stress in Alzheimer disease. Arch Neurol 56:1449-1452. https://doi.org/10.1001/archneur.56.12.1449

31. Cunnane S, Nugent S, Roy M, Courchesne-Loyer A, Croteau E, Tremblay S, Castellano A, Pifferi F, Bocti C, Paquet N (2011) Brain fuel metabolism, aging, and Alzheimer's disease. Nutrition 27:3-20. https://doi.org/10. 1016/j.nut.2010.07.021

32. Rapoport SI, Hatanpää K, Brady DR, Chandrasekaran K (1996) Brain energy metabolism, cognitive function and down-regulated oxidative phosphorylation in Alzheimer disease. Neurodegeneration 5:473-476. https://doi. org/10.1006/neur.1996.0065

33. Du Yan S, Zhu H, Zhu A, Golabek A, Du H, Roher A, Yu J, Soto C, Schmidt AM, Stern D (2000) Receptor-dependent cell stress and amyloid accumulation in systemic amyloidosis. Nat Med 6:643-651. https://doi.org/10. 1038/76216

34. Chuah YK, Basir R, Talib H, Tie TH, Nordin N (2013) Receptor for advanced glycation end products and its involvement in inflammatory diseases. Int J Inflam 2013:403460. https://doi.org/10.1155/2013/403460

35. Li J, Schmidt AM (1997) Characterization and functional analysis of the promoter of RAGE, the receptor for advanced glycation end products. Biol Chem 272:16498-16506. https://doi.org/10.1074/jbc.272.26.16498

36. Obrosova IG (2002) How does glucose generate oxidative stress in peripheral nerve? Int Rev Neurobiol 50:3-35. https://doi.org/10.1016/ s0074-7742(02)50071-4

37. Yan H, Harding JJ (1997) Glycation-induced inactivation and loss of antigenicity of catalase and superoxide dismutase. Biochem J 328:599-605. https://doi.org/10.1042/bj3280599

38. Carnevale D, Mascio G, D’Andrea I, Fardella V, Bell RD, Branchi I, Pallante F, Zlokovic B, Yan SS, Lembo G (2012) Hypertension induces brain $\beta$-amyloid accumulation, cognitive impairment, and memory deterioration through activation of receptor for advanced glycation end products in brain vasculature. Hypertension 60:188-197. https://doi.org/10.1161/ hypertensionaha.112.195511

39. Son SM, Jung ES, Shin HJ, Byun J, Mook-Jung I (2012) A 3 -induced formation of autophagosomes is mediated by RAGE-CaMKKB-AMPK signaling Neurobiol Aging 33(1006):e1011-e1023. https://doi.org/10.1016/j.neuro biolaging.2011.09.039

40. Li X, Du L, Cheng X, Jiang X, Zhang Y, Lv B, Liu R, Wang J, Zhou X (2013) Glycation exacerbates the neuronal toxicity of $\beta$-amyloid. Cell Death Dis 4:e673-e673. https://doi.org/10.1038/cddis.2013.180

41. Matrone C, Djellou M, Taglialatela G, Perrone L (2015) Inflammatory risk factors and pathologies promoting Alzheimer's disease progression: is RAGE the key? Histol Histopathol 30:125-139. https://doi.org/10.14670/ $\mathrm{HH}-30.125$
42. Du Yan S, Chen X, Fu J, Chen M, Zhu H, Roher A, Slattery T, Zhao L, Nagashima M, Morser J (1996) RAGE and amyloid- $\beta$ peptide neurotoxicity in Alzheimer's disease. Nature 382:685-691. https://doi.org/10.1038/ $382685 \mathrm{a} 0$

43. Yan SS, Chen D, Yan S, Guo L, Chen JX (2012) RAGE is a key cellular target for a $\beta$-induced perturbation in Alzheimer's disease. Front Biosci (Schol Ed) 4:240. https://doi.org/10.2741/265

44. Yamagishi SI, Matsui T (2010) Soluble form of a receptor for advanced glycation end products (sRAGE) as a biomarker. Front Biosci (Elite Ed) 2:1184-1195. https://doi.org/10.2741/e178

45. Scheffler K, Stenzel J, Krohn M, Lange C, Hofrichter J, Schumacher T, Bruning T, Plath A-S, Walker L, Pahnke J (2011) Determination of spatial and temporal distribution of microglia by $230 \mathrm{~nm}$-high-resolution, highthroughput automated analysis reveals different amyloid plaque populations in an APP/PS1 mouse model of Alzheimer's disease. Curr Alzheimer Res 8:781-788. https://doi.org/10.2174/156720511797633179

46. Hickman SE, Allison EK, El Khoury J (2008) Microglial dysfunction and defective $\beta$-amyloid clearance pathways in aging Alzheimer's disease mice. J Neurosci 28:8354-8360. https://doi.org/10.1523/JNEUROSCI.061608.2008

47. Hanisch U-K, Kettenmann H (2007) Microglia: active sensor and versatile effector cells in the normal and pathologic brain. Nat Neurosci 10:13871394. https://doi.org/10.1038/nn1997.

48. Carrero I, Gonzalo M, Martin B, Sanz-Anquela J, Arevalo-Serrano J, Gonzalo-Ruiz A (2012) Oligomers of beta-amyloid protein (aß1-42) induce the activation of cyclooxygenase- 2 in astrocytes via an interaction with interleukin-1 beta, tumour necrosis factor-alpha, and a nuclear factor kappa-B mechanism in the rat brain. Exp Neurol 236:215-227. https://doi. org/10.1016/j.expneurol.2012.05.004

49. Medeiros R, LaFerla FM (2013) Astrocytes: conductors of the Alzheimer disease neuroinflammatory symphony. Exp Neurol 239:133-138. https:// doi.org/10.1016/j.expneurol.2012.10.007

50. Hartlage-Rübsamen M, Zeitschel U, Apelt J, Gärtner U, Franke H, Stahl T, Günther A, Schliebs R, Penkowa M, Bigl V (2003) Astrocytic expression of the Alzheimer's disease $\beta$-secretase (BACE1) is stimulus-dependent. Glia 41:169-179. https://doi.org/10.1002/glia.10178

51. Kandimalla R, Thirumala V, Reddy PH (2017) Is Alzheimer's disease a type 3 diabetes? A critical appraisal. Biochim Biophys Acta Mol Basis Dis 1863:1078-1089. https://doi.org/10.1016/j.bbadis.2016.08.018

52. Burns A, lliffe S (2009) Alzheimer's disease. BMJ 338:b158. https://doi.org/ 10.1136/bmj.b158

53. Muacevic A, Adler J, Nisar O, Pervez H, Mandalia B, Waqas M, Sra H (2021) Type 3 diabetes mellitus: a link between Alzheimer's disease and type 2 diabetes mellitus. Cureus 12:e11703. https://doi.org/10.7759/cureus. 11703

54. Nguyen TT, Ta QTH, Nguyen TKO, Nguyen TTD, Van Giau V (2020) Type 3 diabetes and its role implications in Alzheimer's disease. Int J Mol Sci 21:3165. https://doi.org/10.3390/ijms21093165

55. De la Monte SM, Wands JR (2008) Alzheimer's disease is type 3 diabetes-evidence reviewed. J Diabetes Sci Technol 2:1101-1113. https://doi. org/10.1177/193229680800200619

56. Pugazhenthi S, Qin L, Reddy PH (2017) Common neurodegenerative pathways in obesity, diabetes, and Alzheimer's disease. Biochim Biophys Acta Mol Basis Dis 1863:1037-1045. https://doi.org/10.1016/j.bbadis.2016. 04.017

57. Yamagishi SI (2011) Role of advanced glycation end products (AGEs) and receptor for AGEs (RAGE) in vascular damage in diabetes. Exp Gerontol 46:217-224. https://doi.org/10.1016/j.exger.2010.11.007

58. Lue L-F, Andrade C, Sabbagh M, Walker D (2012) Is there inflammatory synergy in type II diabetes mellitus and Alzheimer's disease? Int J Alzheimers Dis 2012:918680. https://doi.org/10.1155/2012/918680

59. Shieh JCC, Huang PT, Lin YF (2020) Alzheimer's disease and diabetes: insulin signaling as the bridge linking two pathologies. Mol Neurobiol 57:1966-1977. https://doi.org/10.1007/s12035-019-01858-5

60. Takeda A, Yasuda T, Miyata T, Mizuno K, Li M, Yoneyama S, Horie K, Maeda K, Sobue G (1996) Immunohistochemical study of advanced glycation end products in aging and Alzheimer's disease brain. Neurosci Lett. 221:17-20. https://doi.org/10.1016/s0304-3940(96)13275-4

61. Goldwaser EL, Acharya NK, Sarkar A, Godsey G, Nagele RG (2016) Breakdown of the cerebrovasculature and blood-brain barrier: a mechanistic 
link between diabetes mellitus and Alzheimer's disease. J Alzheimers Dis 54:445-456. https://doi.org/10.3233/JAD-160284

62. Lee BW, Chae HY, Kwon SJ, Park SY, Ihm J, Ihm S-H (2010) RAGE ligands induce apoptotic cell death of pancreatic $\beta$-cells via oxidative stress. Int J Mol Med 26:813-818

63. Tini G, Scagliola R, Monacelli F, La Malfa G, Porto I, Brunelli C, Rosa GM (2020) Alzheimer's disease and cardiovascular disease: a particular association. Cardiol Res Pract 2020:2617970. https://doi.org/10.1155/2020/ 2617970

64. Zlokovic BV (2011) Neurovascular pathways to neurodegeneration in Alzheimer's disease and other disorders. Nat Rev Neurosci 12:723-738. https://doi.org/10.1038/nrn3114

65. Alzheimer's Association (2016) 2016 Alzheimer's disease facts and figures. Alzheimers Dement 12:459-509. https://doi.org/10.1016/j.jalz.2016.03. 001.

66. de la Torre JC (2006) How do heart disease and stroke become risk factors for Alzheimer's disease? Neurol Res 28:637-644. https://doi.org/10.1179/ $016164106 \times 130362$

67. Stakos DA, Stamatelopoulos K, Bampatsias D, Sachse M, Zormpas E, Vlachogiannis NI, Tual-Chalot S, Stellos K (2020) The Alzheimer's disease amyloid-beta hypothesis in cardiovascular aging and disease: JACC focus seminar. J Am Coll Cardiol 75:952-967. https://doi.org/10.1016/j.jacc. 2019.12.033

68. Prasad K (2021) AGE-RAGE stress and coronary artery disease. Int J Angiol 30:4-14. https://doi.org/10.1055/s-0040-1721813

69. Iadecola C, Davisson RL (2008) Hypertension and cerebrovascular dysfunction. Cell Metab 7:476-484. https://doi.org/10.1016/j.cmet.2008.03. 010

70. Skoog I, Gustafson D (2002) Hypertension and related factors in the etiology of Alzheimer's disease. Ann N Y Acad Sci 977:29-36. https://doi.org/ 10.1111/j.1749-6632.2002.tb04796.x

71. Scuteri A, Nilsson PM, Tzourio C, Redon J, Laurent S (2011) Microvascular brain damage with aging and hypertension: pathophysiological consideration and clinical implications. J Hypertens 29:1469-1477. https://doi. org/10.1097/HJH.0b013e328347cc17

72. Uiterwijk R, Huijts M, Staals J, Rouhl RP, De Leeuw PW, Kroon AA, Van Oostenbrugge RJ (2016) Endothelial activation is associated with cognitive performance in patients with hypertension. Am J Hypertens 29:464-469. https://doi.org/10.1093/ajh/hpv122

73. Droste D, Ritter M, Dittrich R, Heidenreich S, Wichter T, Freund M, Ringelstein E (2003) Arterial hypertension and ischaemic stroke. Acta Neurol Scand 107:241-251. https://doi.org/10.1034/j.1600-0404.2003.00098.x

74. Carnevale D, Perrotta M, Lembo G, Trimarco B (2015) Pathophysiological links among hypertension and Alzheimer's. High Blood Press Cardiovasc Prev 23:3-7. https://doi.org/10.1007/s40292-015-0108-1

75. Laakso M (1999) Hyperglycemia and cardiovascular disease in type 2 diabetes. Diabetes 48:937-942. https://doi.org/10.2337/diabetes.48.5.937

76. Nelson AR, Sweeney MD, Sagare AP, Zlokovic BV (2016) Neurovascular dysfunction and neurodegeneration in dementia and Alzheimer's disease. Biochim Biophys Acta Mol Basis Dis 1862:887-900. https://doi.org/ 10.1016/j.bbadis.2015.12.016

77. Yarchoan M, Xie SX, Kling MA, Toledo JB, Wolk DA, Lee EB, Van Deerlin V, Lee VM-Y, Trojanowski JO, Arnold SE (2012) Cerebrovascular atherosclerosis correlates with Alzheimer pathology in neurodegenerative dementias. Brain 135:3749-3756 https://doi.org/10.1093/brain/aws271

78. Arntzen KA, Schirmer H, Johnsen SH, Wilsgaard T, Mathiesen EB (2012) Carotid atherosclerosis predicts lower cognitive test results: a 7-year follow-up study of 4,371 stroke-free subjects-the troms $\varnothing$ study. Cerebrovasc Dis 33:159-165. https://doi.org/10.1159/000334182

79. Zhong W, Cruickshanks KJ, Schubert CR, Acher CW, Carlsson CM, Klein BE, Klein R, Chappell RJ (2012) Carotid atherosclerosis and 10-year changes in cognitive function. Atherosclerosis 224:506-510. https://doi.org/10. 1016/j.atherosclerosis.2012.07.024

80. Halliday MR, Rege SV, Ma Q, Zhao Z, Miller CA, Winkler EA, Zlokovic BV (2016) Accelerated pericyte degeneration and blood-brain barrier breakdown in Apolipoprotein E4 carriers with Alzheimer's disease. J Cereb Blood Flow Metab 36:216-227. https://doi.org/10.1038/jcbfm. 2015.44

81. Sparks DL (1997) Coronary artery disease, hypertension, apoe, and cholesterol: a link to Alzheimer's disease? Ann N Y Acad Sci 826:128-146. https://doi.org/10.1111/j.1749-6632.1997.tb48466.x

82. Mehta PK, Griendling KK (2007) Angiotensin II cell signaling: physiological and pathological effects in the cardiovascular system. Am J Physiol Cell Physiol 292:C82-C97. https://doi.org/10.1152/ajpcell.00287.2006

83. Duprez DA (2006) Role of the renin-angiotensin-aldosterone system in vascular remodeling and inflammation: a clinical review. J Hypertens 24:983-991. https://doi.org/10.1097/01.hjh.0000226182.60321.69

84. Liu S, Liu J, Miura Y, Tanabe C, Maeda T, Terayama Y, Turner AJ, Zou K, Komano $\mathrm{H}$ (2014) Conversion of a $\beta 43$ to a $\beta 40$ by the successive action of angiotensin-converting enzyme 2 and angiotensin-converting enzyme. J Neurosci Res 92:1178-1186. https://doi.org/10.1002/jnr.23404

85. Hsu C-Y, Huang C-C, Chan W-L, Huang P-H, Chiang C-H, Chen T-J, Chung C-M, Lin S-J, Chen J-W, Leu H-B (2012) Angiotensin-receptor blockers and risk of Alzheimer's disease in hypertension population-a nationwide cohort study. Circ J 77:405-410 https://doi.org/10.1253/circj.cj-12-0658

86. Saavedra JM (2016) Evidence to consider angiotensin II receptor blockers for the treatment of early Alzheimer's disease. Cell Mol Neurobiol 36:259-279. https://doi.org/10.1007/s10571-015-0327-y

87. Jackson L, Eldahshan W, Fagan SC, Ergul A (2018) Within the brain: the renin angiotensin system. Int J Mol Sci 19:876. https://doi.org/10.3390/ ijms 19030876

88. Gebre AK, Altaye BM, Atey TM, Tuem KB, Berhe DF (2018) Targeting reninangiotensin system against Alzheimer's disease. Front Pharmacol 9:440. https://doi.org/10.3389/fphar.2018.00440

89. Scivittaro V, Ganz MB, Weiss MF (2000) AGEs induce oxidative stress and activate protein kinase C-beta(II) in neonatal mesangial cells. Am J Physiol Renal Physiol 278:F676-F683. https://doi.org/10.1152/ajprenal.2000.278.4. F676

90. Zhou Q, Liu N, Xie P (1997) Expression of receptor for advanced glycosylation end products (AGEP) and inhibition of AGEP-induced cytosolic calcium elevation by diltiazem in cultured rat aortic smooth muscle cells. Zhongguo Yao Li Xue Bao 18:425-430

91. Kehoe PG (2009) Angiotensins and Alzheimer's disease: a bench to bedside overview. Alzheimers Res Ther 1:3. https://doi.org/10.1186/alzrt3

92. Faraco G, Park L, Zhou P, Luo W, Paul SM, Anrather J, ladecola C (2016) Hypertension enhances a $\beta$-induced neurovascular dysfunction, promotes $\beta$-secretase activity, and leads to amyloidogenic processing of APP. J Cereb Blood Flow Metab 36:241-252. https://doi.org/10.1038/jcbfm. 2015.79

93. Fukami K, Ueda S, Yamagishi SI, Kato S, Inagaki Y, Takeuchi M, Motomiya Y, Bucala R, lida S, Tamaki K (2004) AGEs activate mesangial TGF- $\beta$-Smad signaling via an angiotensin II type I receptor interaction. Kidney Int 66:2137-2147. https://doi.org/10.1111/j.1523-1755.2004.66004.x

94. Ikemoto F, Song G-B, Tominaga M, Yamamoto K (1988) Oxidation-induced increase in activity of angiotensin converting enzyme in the rat kidney. Biochem Biophys Res Commun 153:1032-1037. https://doi.org/10.1016/ s0006-291x(88)81332-9

95. Schupp N, Schinzel R, Heidland A, Stopper H (2005) Genotoxicity of advanced glycation end products: involvement of oxidative stress and of angiotensin II type 1 receptors. Ann N Y Acad Sci 1043:685-695. https:// doi.org/10.1196/annals.1333.079

96. Vasdev S, Gill V, Singal P (2007) Role of advanced glycation end products in hypertension and atherosclerosis: therapeutic implications. Cell Biochem Biophys 49:48-63. https://doi.org/10.1007/s12013-007-0039-0

\section{Publisher's Note}

Springer Nature remains neutral with regard to jurisdictional claims in published maps and institutional affiliations. 